\title{
The levels of serum pro-calcitonin and high-sensitivity C-reactive protein in the early diagnosis of chronic obstructive pulmonary disease during acute exacerbation
}

\author{
DEJIE GAO ${ }^{1}$, XINCAN CHEN $^{1}, \mathrm{HE} \mathrm{WU}^{1}, \mathrm{HAIDONG} \mathrm{WEI}^{2}$ and JINLING WU ${ }^{3}$ \\ ${ }^{1}$ Department of Tuberculosis, Binzhou Tuberculosis Control Center, Binzhou Medical College, Binzhou, Shandong 250000; \\ ${ }^{2}$ Department of Laboratory, Binzhou Center Hospital, Binzhou Medical College, Binzhou, Shandong 256603; \\ ${ }^{3}$ Department of Respiratory Medicine, Binzhou Center Hospital, \\ Binzhou Medical College, Binzhou, Shandong 251700, P.R. China
}

Received January 30, 2017; Accepted May 4, 2017

DOI: $10.3892 /$ etm.2017.4496

\begin{abstract}
The level of of procalcitonin (PCT) and high-sensitivity C-reactive protein (hs-CRP) in the acute exacerbation of COPD (AECOPD) was investigated. Total of 20 patients with acute exacerbation of COPD who were admitted to the Department of Respiratory Medicine, Binzhou Center Hospital in the period of October 2012 to April 2015 were enrolled in the AECOPD group. According to the color of the sputum, the patients with AECOPD were divided into purulent sputum group $(n=8)$ and non-purulent sputum group $(n=12)$. In addition, 15 healthy people from the outpatient medical center were also selected as healthy control group. The levels of serum PCT and hs-CRP in both groups were determined by chemiluminescence and immunoturbidimetry, respectively for the comparison analysis. The serum PCT concentration in AECOPD group was $2.07 \pm 5.57 \mathrm{ng} / \mathrm{ml}$, while that in healthy control group was $0.21 \pm 0.17 \mathrm{ng} / \mathrm{ml}$. Significant difference was found between serum PCT levels in the two groups $(\mathrm{p}<0.05)$. The serum concentration of hs-CRP in AECOPD group was $3.66 \pm 3.95 \mathrm{mg} / \mathrm{l}$, which is significantly higher than that of the healthy control group $(0.49 \pm 0.17)(\mathrm{p}<0.001)$. In AECOPD group, the sensitivity of PCT, hs-CRP and white blood cell count was 75, 40 and $40 \%$, respectively, while the specificity was 80,100 and $100 \%$, respectively, indicating that PCT has higher sensitivity than hs-CRP and white blood cell count $(\mathrm{p}<0.05)$. However, no significant difference was found in specificity among these three methods ( $p>0.05)$. PCT level of the patients in purulent sputum group was $3.72 \pm 8.80 \mathrm{ng} / \mathrm{ml}$, while that of the patients in non-purulent sputum group was
\end{abstract}

Correspondence to: Dr Jinling Wu, Department of Respiratory Medicine, Binzhou Center Hospital, Binzhou Medical College, 108 Huancheng, Binzhou, Shandong 251700, P.R. China

E-mail:wr229o@163.com

Key words: chronic obstructive pulmonary disease, PCT, hs-CRP, diagnosis, acute exacerbation
$0.97 \pm 1.06 \mathrm{ng} / \mathrm{ml}$. The serum hs-CRP level of patients in purulent sputum group was $4.94 \pm 4.60 \mathrm{mg} / \mathrm{l}$, while that of the patients in non-purulent sputum group was $(2.80 \pm 3.38 \mathrm{mg} / \mathrm{l})$. Both the above parameters showed no significant difference between the purulent sputum group and the non-purulent sputum group ( $\mathrm{p}>0.05)$. In conclusion, serum PCT and hs-CRP levels can be used as auxiliary diagnosis index for acute exacerbation of COPD. Measurement of serum PCT and hs-CRP levels in patients with AECOPD may be helpful in guiding antibacterial drug therapy.

\section{Introduction}

Chronic obstructive pulmonary disease (COPD) is a preventable and treatable disease characterized by the airflow obstruction. COPD mainly affects the lungs, but can also bring adverse effects to other parts of the body. Due to the high morbidity, mortality, and heavy social and economic burden on the family of patients, COPD has become a critical threat to public health. There are many etiological factors behind the acute exacerbations of chronic obstructive pulmonary disease (AECOPD) and the pathogenesis has been revealed to be complex in these cases. Many studies have revealed that $\sim 80 \%$ cases of AECOPD were caused by viral or bacterial infection, of which $50 \%$ caused by the bacterial infections (1-3). Although the role of bacterial infection in acute exacerbation of COPD is still controversial (2). Lower respiratory tract infection with acute exacerbation is the leading cause of death in patients with moderate to severe COPD (3-6). The pathogenesis of COPD is not yet fully understood. It has been widely accepted that COPD is characterized by chronic inflammation of the airways, pulmonary parenchyma pulmonary vessels, and a variety of media released by activated inflammatory cells. Many modalities have been used for the early diagnosis of COPD. Currently, inflammatory markers can also be used for COPD. These markers include serum procalcitonin (PCT), serum interleukin-6 (IL-6), IL-8 and IL-18, tumor necrosis factor- $\alpha$ (TNF- $\alpha$ ), copeptin, soluble CD14, macrophage inflammatory protein-1 $\alpha$ (MIP-1 $\alpha)$ and white blood cell count (WBC). Among the above-mentioned 
inflammatory markers, C-reactive protein (CRP), IL-6, PCT and $\mathrm{WBC}$ are commonly used in clinical practice.

PCT, which is a propeptide glycoprotein of calcitonin (CT) is usually produced by thyroid C cells (7). However, during the systemic infection, tissues other than thyroid can also secrete PCT, resulting in increased PCT levels $(8,9)$. PCT is secreted in acute phases and considered to be response protein. At the early stage of inflammation, PCT appeared synchronized or earlier than CRP $(8,9)$. As a biological biomarker, levels of serum PCT has been shown to be increased in bacterial infections but not in the viral infections and nonspecific inflammatory conditions $(10,11)$. The increased levels of PCT in the serum also reflect the severity of the disease. The higher the serum PCT level, the more severe the condition will be. Continuously increasing levels of PCT often reflects poor prognosis. Serum PCT level will significantly decrease with proper treatment (12). PCT has been considered as one of the best biological indicators for bacterial infection. CRP is also an acute phase protein synthesized in the liver. The synthesis of CRP is closely related to the inflammatory cytokines. The levels of PCT, which have a close relationship with inflammatory response, are an important biochemical indicator of the inflammatory response. In recent years, the application of latex-enhanced immunoturbidimetric techniques has greatly improved the sensitivity of CRP measurement, and the accuracy is also high with low concentration of CRP (such as $0.15-10 \mathrm{mg} / \mathrm{l})$. CRP measured by these methods is called hs-CRP (13). CRP level is an early and sensitive classic indicator of most o bacterial infections and has been widely used in the surveillance and prognosis of infectious diseases $(14,15)$. However, CRP is a classic laboratory indicator of the severity of the bacterial infection, but it cannot distinguish between the bacterial and non-bacterial inflammatory response, in addition, the CRP level also showed no response during the early stages of severe infection. Studies on the determination of bacterial infection have shown that PCT has both the highest sensitivity and specificity among all the biological markers. PCT is also better than CRP in the early diagnosis and prognosis (16).

In this study, we have evaluated the serum PCT and hs-CRP levels and further comparison were done between AECOPD patients and the healthy controls. The sensitivity and specificity of two biological markers were also compared. In addition, the levels of serum PCT and hs-CRP in AECOPD patients with different sputum traits were compared and the clinical values of these two indicators in acute exacerbation of COPD are also discussed.

\section{Patients and methods}

\section{Basic information}

AECOPD group. In this group, a total of 20 patients were selected, who were admitted to the Department of Respiratory Medicine, Binzhou Center Hospital in the time period of October 2012 to April 2015. Out of these 20 patients, 12 were males and 8 were female patients. The age range was $52-93$ years with a mean age of $72.40 \pm 18.78$ years.

Healthy control group. In this group, a total of 15 cases were selected including 9 males and 6 females from the outpatient health center. The age range was 60 to 79 years with a mean age of $68.87 \pm 5.87$ years. The following information were collected from each patient regarding age, gender, primary underlying disease, complications, sputum color, body temperature, respiratory rate, blood pressure, heart rate, state of consciousness, blood gas analysis, white blood cell count and percentage, and medical imaging results. This study was approved by the Ethics Committee of Binzhou Center Hospital. Signed written informed consents were obtained from all participants before the study.

Selection criteria for AECOPD group. The selection criteria were decided by comprehensive analysis of the clinical manifestations, history of exposure to risk factors, physical signs and the laboratory tests. The main symptoms of COPD includes chronic cough, expectoration/or dyspnea and history of exposure to risk factors. Incomplete reversible airflow obstruction was considered to be a prerequisite for the diagnosis of COPD. Pulmonary function tests were considered as the gold standard tests for the diagnosis of COPD. If the levels of FEV1/FVC were $<70 \%$ after the treatment of bronchodilator, it was considered as an incomplete reversible airflow obstruction. Pulmonary function test was applied to all the patients with a history of smoking and (or) environmental occupational pollution contact history, cough, expectoration or dyspnea. AECOPD is defined as a persistent exacerbation of a patient's condition beyond the usual condition, requiring a change in conventional medication of basic COPD, and also include the relevant description which is mentioned in the 2002 guidelines by the European Respiratory Society (17). The guidelines during the course of the disease includes many sign and symptoms such as patient usually show short-term cough, expectoration, shortness of breath and/or increased wheezing, increased sputum, purulent or mucopurulent purulent sputum, the symptom can also be accompanied by fever and other symptoms of significantly increased inflammatory manifestations.

Exclusion criteria. The patients with other chronic respiratory diseases such as bronchiectasis, active tuberculosis, asthma, pulmonary embolism and so on, patients with bacterial infections encountered outside the respiratory system, patients with lung cancer, thyroid myeloid cell carcinoma and other malignant tumor were excluded from the AECOPD group. Patients with serious immune deficiency and immune system diseases such as connective tissue disease, gout, and so on, patients with mental illness hindering other participants to complete the tests. The ones with respiratory disease and other related diseases should be excluded from healthy control group.

\section{Methods}

Sputum specimen collection. Natural sputum method was applied to collect the sample. Sputum was collected in the morning after cold water gargle and deep cough. Sterile container was used to collect sputum specimens without saliva. Patients with opacity or milky sputum were classified as non-purulent sputum group. Patients with dry cough and no sputum were also classified as non-purulent sputum. Patients with yellow, green or brown sputum were classified as purulent sputum.

Measurement of serum PCT and hs-CRP levels. Collection and preservation of blood samples: venous blood $\sim 3 \mathrm{ml}$ was 
withdrawn from patients by the next day after the admission with an empty stomach. The blood samples were placed into plugged sterile test tubes and centrifuged at 2,500 x g after solidification at room temperature $25^{\circ} \mathrm{C}$. The serum samples were stored at $-20^{\circ} \mathrm{C}$ for further tests.

Determination of serum PCT levels. Chemiluminescence method was used to measure the serum PCT levels. PCT assay kit (chemiluminescence method) produced by Shenzhen New Industry Biomedical Engineering Co., Ltd. was used for the analysis. The normal reference value provided by the laboratory was $0-0.20 \mathrm{ng} / \mathrm{ml}$, which was applied in this study. Lumino analyzer (Lumino, Los Gatos, CA, USA) was used as the PCT detector. According to the manual instruction, all the operations were performed by the professional personnel with quality control services.

Measurement of serum hs-CRP levels. Serum hs-CRP levels were measured by immunoturbidimetry. The high sensitivity CRP reagent provided by Dade Behring Marburg $\mathrm{GmbH}$ (Marburg, Germany), was used in this study. The normal reference value provided by the laboratory was $0-2.1 \mathrm{mg} / \mathrm{l}$, which was applied in this study. For the estimation of hs-CRP detector, 7600 automatic biochemical analyzer (Hitachi, Tokyo, Japan) was used according to the manual instruction; all the operations (double standard and double tube measurement) were performed by professional personnel.

Statistical analysis. All measurement data were expressed as mean \pm standard deviation (SD). The count data i.e. sensitivity, specificity were analyzed by the Chi-square test. The data were analyzed with SPSS version 11.0 statistical software (IBM, Armonk, NY, USA). The test standard $\alpha=0.05, \mathrm{p}<0.05$ was considered to be statistically significant.

\section{Results}

The comparison of PCT and hs-CRP levels between AECOPD group and healthy control group. The serum PCT concentration in 20 AECOPD patients was $2.07 \pm 5.57 \mathrm{ng} / \mathrm{ml}$, while that in 15 healthy controls was $0.21 \pm 0.17 \mathrm{ng} / \mathrm{ml}$. The significant difference was found between the two groups with statistical significant p-value of $<0.05$. The concentration of serum hs-CRP was $3.66 \pm 3.95 \mathrm{mg} / \mathrm{l}$ in AECOPD group and $0.49 \pm 0.17 \mathrm{mg} / \mathrm{lin}$ 15 healthy controls, respectively. There was also statistically significant difference between the two groups with significant p-value of $<0.001$ (Table I).

The sensitivity and specificity of serum PCT, hs-CRP and $W B C$ count in diagnosis of AECOPD. Among the 20 AECOPD patients, 15 cases had higher PCT levels than $0.15 \mathrm{ng} / \mathrm{ml}$ and the positive rate was $75 \%$. Eight cases had higher hs-CRP levels than $2.1 \mathrm{mg} / \mathrm{l}$ and the positive rate was $40 \%$. Eight cases had white blood cell count numbers higher than $10 \times 10^{9} / 1$ and the positive rate was $40 \%$. Therefore, the sensitivity of PCT, hs-CRP, white blood cell count was 75, 40 and 40\%, respectively. Among the 15 health individuals, 3 cases had higher PCT levels than $0.15 \mathrm{ng} / \mathrm{ml}$ and the positive rate was $20 \%$. Not a single case had hs-CRP levels higher than $2.1 \mathrm{mg} / \mathrm{l}$ and the positive rate was 0 . Again not a single case had white blood cell count number higher than $10 \times 10^{9} / 1$ and the positive rate was $0 \%$. Therefore, the specificity of PCT, hs-CRP,
Table I. The comparison of PCT and hs-CRP levels between AECOPD group and healthy control group.

\begin{tabular}{lccc}
\hline Groups & Cases & PCT (ng/ml) & hs-CRP (mg/l) \\
\hline AECOPD group & 20 & $2.07 \pm 5.57$ & $3.66 \pm 3.95$ \\
Healthy control group & 15 & $0.21 \pm 0.17$ & $0.49 \pm 0.17$ \\
Z-value & & -2.069 & -3.384 \\
P-value & & 0.039 & $<0.001$ \\
\hline
\end{tabular}

PCT, procalcitonin; hs-CRP, high-sensitivity C-reactive protein; AECOPD, acute exacerbation of COPD.

Table II. The sensitivity and specificity of serum PCT, hs-CRP and WBC count in diagnosis of AECOPD.

\begin{tabular}{lccc}
\hline Positive cut-off & PCT (\%) & hs-CRP (\%) & WBC (\%) \\
\hline Sensitivity & $75^{\mathrm{a}}$ & 40 & 40 \\
Specificity & 80 & 100 & 100 \\
\hline
\end{tabular}

${ }^{a}$ The sensitivity of PCT is significantly higher than that of hs-CRP $(\mathrm{p}<0.05)$. PCT, procalcitonin; hs-CRP, high-sensitivity C-reactive protein; AECOPD, acute exacerbation of COPD; WBC, white blood cell

white blood cell count was 80,100 and $100 \%$, respectively. The sensitivity and specificity of serum PCT, hs-CRP of WBC count in diagnosis of AECOPD were evaluated in both groups (Table II). Significant difference was found in sensitivity between PCT and hs-CRP $(\mathrm{p}<0.05)$ but not found in specificity $(\mathrm{p}>0.05)$ between these 2 groups. The sensitivity of PCT was significantly different from that of WBC $(\mathrm{p}<0.05)$ but specificity of PCT was not significantly different from that of WBC ( $p>0.05)$. The sensitivity of Hs-CRP was significantly different from that of WBC $(\mathrm{p}<0.05)$ but specificity of Hs-CRP was not significantly different from that of WBC $(\mathrm{p}>0.05)$.

The comparison of serum PCT and hs-CRP levels between patients with and without purulent sputum. Among the patients with acute exacerbation of COPD, the concentration of PCT in patients with purulent sputum was $3.72 \pm 8.8 \mathrm{ng} / \mathrm{ml}$ while the serum concentration of PCT was $0.97 \pm 1.06 \mathrm{ng} / \mathrm{ml}$ in non-purulent sputum patients. The data revealed nonsignificant difference between these two groups. PCT concentration in patients with purulent sputum was $4.94 \pm 4.60 \mathrm{mg} / \mathrm{l}$, while the serum concentration of hs-CRP was $2.80 \pm 3.38 \mathrm{mg} / 1$ in non-purulent sputum patients. Again, no significant difference was found between these two groups (Table III).

\section{Discussion}

Besides lower respiratory tract bacterial infections, AECOPD can also be caused by viral infections, other atypical pathogens and by some non-infectious factors. However, it is difficult to obtain accurate etiological factors for AECOPD cases in many patients. In addition, it is difficult to distinguish the clinical 
Table III. The comparison of serum PCT and hs-CRP levels between patients with and without purulent sputum.

\begin{tabular}{lccc}
\hline Groups & Cases & PCT $(\mathrm{ng} / \mathrm{ml})$ & hs-CRP $(\mathrm{mg} / \mathrm{l})$ \\
\hline $\begin{array}{l}\text { Purulent sputum } \\
\text { group }\end{array}$ & 8 & $3.72 \pm 8.8$ & $4.94 \pm 4.60$ \\
$\begin{array}{l}\text { None-purulent } \\
\text { sputum group }\end{array}$ & 12 & $0.97 \pm 1.06$ & $2.80 \pm 3.38$ \\
$\begin{array}{l}\text { Z-value } \\
\text { P-value }\end{array}$ & & -0.194 & -1.389 \\
\hline
\end{tabular}

PCT, procalcitonin; hs-CRP, high-sensitivity C-reactive protein.

manifestations of viruses and other atypical pathogen infections, and bacterial infections. Studies that tried to identify other biomarkers that reflect bacterial infection in AECOPD patients failed to get positive results (15-18). As an inflammatory biomarker, it was believed that serum PCT was the only increased biomarker in the systemic bacterial infections. But now serum PCT has also shown application values in the diagnosis of local bacterial infections with increased sensitivity of detection methods and reduced diagnostic threshold $(0.5 \mu \mathrm{g} / \mathrm{l}$ was used as a diagnostic threshold for bacterial infection in the past). Polzin et al (19) concluded that, the serum PCT levels of the patients with infectious lung disease increased significantly when compared with patients with non-infectious lung disease (20). In another study conducted by Pazarli et al (21) the serum PCT levels of patients with AECOPD or COPD were measured in stable period. They also carried out quantitative culture of induced sputum, The results revealed that the serum PCT levels were significantly higher in acute exacerbation stage than that in the stable phase. The levels of serum PCT in patients with acute exacerbation and positive result in bacterial culture is significant higher than that of the patients with negative result in bacterial culture. For the patients who gave negative result in the bacterial culture, revealed no statistical significant difference in the PCT levels between the patients in the stable stage and the patients with acute exacerbations. This study also showed that the serum PCT level of patients with acute exacerbation of COPD was significantly higher than that of the healthy control group. Our data were also consistent with the previous study of Tanriverdi et al (22), reveling that the serum PCT concentration can also be used as an auxiliary diagnostic index in the diagnosis of lower respiratory tract bacterial infection in patients with acute exacerbation of COPD.

As a sensitive biomarker of nonspecific inflammatory reactions, the levels of serum CRP are closely related to the severity of inflammatory reactions. Serum CRP levels can also be increased by inflammation, infection and the tissue damage. The further increased degree depends on the intensity of inflammatory stimulus (23). Dev et al have shown that CRP may be considered as an indicator of acute exacerbation of COPD, but not necessarily an indicator of the bacterial infections (24). Among the 36 potential plasma biomarkers tested by Hurst $e t a l$ in the identification of acute exacerbations of
COPD and severe deterioration prediction, CRP is the most selective biomarker amongst the total 36 biomarkers. However, CRP alone did not show any significant sensitivity or significant specificity (25). Therefore, Hurst et al believed that CRP can be used in the diagnosis of acute exacerbation of COPD in the presence of the increased main symptoms of COPD (25). The retrospective study, carried out by Bircan et al (26), concluded that there was no statistical significant difference in serum CRP levels between the control group and the patients with COPD in stable stage $(\mathrm{p}>0.05)$. They also revealed that the serum CRP levels of patients with COPD in stable stage is significantly different from that of the patients with acute exacerbation of COPD $(p=0.002)$; the levels of serum CRP were lower than $10 \mathrm{mg} / \mathrm{l}$ in both control group and patients with COPD in stable stage, indicating that the increased serum CRP levels may be an important marker of acute exacerbation of COPD. This study also showed that hs-CRP levels of patients with acute exacerbation of COPD were significantly higher than that of healthy control group, indicating that serum hs-CRP level can be used as an auxiliary diagnosis index for the lower respiratory tract bacterial infection in patients with acute exacerbation of COPD.

As a biological indicator, PCT levels increase during the bacterial infections, but no significant change was found in the viral infections and non-specific inflammatory diseases $(10,11)$. Serum CRP lacks the specificity as a biomarker of the bacterial infections. In the study of bacterial infection determination, Shimetani et al have found that the PCT was the best biomarker in the sensitivity and specificity. They also concluded that the PCT is better than the CRP in the early diagnosis, prognosis and other aspects of disease progression (16). This study has shown that sensitivity of PCT was significantly higher than that of hs-CRP and peripheral white blood cell count in diagnosis of acute exacerbation of COPD $(p<0.05)$. Both the white blood cell count and the hs-CRP gave high specificity in the diagnosis of acute exacerbation of COPD but showed no significant difference to that of PCT, indicating that PCT can be used as a diagnostic biomarker of acute exacerbation of COPD, and it is better than CRP and white blood cell count.

It is generally accepted that the tracheal and the bronchial infections are the main reasons of acute exacerbation of COPD, and bacterial infection is considered to be the most common cause of acute exacerbation of COPD. However, bacterial colonization is common during stable phases in the lower respiratory tract of patients with COPD. Routine bacterial culture of sputum is often unreliable in demonstrating the bacterial infections, which are responsible for acute exacerbations of COPD. In a prospective study, Stockley et al (27) showed a significantly increased positive rate in bacterial culture of purulent sputum. Gompertz et al (28) have also found that the sputum pathogen concentration of most of the patients with purulent sputum were equal or even higher than $107 \mathrm{CFU} / \mathrm{ml}$, while that of most of the patients with sticky sputum were lower than $107 \mathrm{CFU} / \mathrm{ml}$. The symptoms in patients with sticky sputum could easily recover without any antibiotic treatment. Therefore, we can simply use the color of sputum as a clinical rapid determination of the existing bacterial infection in AECOPD. Monsó et al (29) found that the sputum bacterial culture of the 159 patients with acute 
exacerbation of COPD showed that the bacterial positive rate in purulent sputum group was significantly higher than that in the white sputum group $(\mathrm{p}<0.001)$. This revealed that the positive rate in the bacterial culture of AECOPD patients with purulent sputum is significantly higher than that of the AECOPD patients with white sticky sputum, and can be used as indications of antimicrobial therapy. PCT serum kinetic study have also found that the dynamic detection of PCT levels can be used as effective guide for the use of antimicrobial drugs, and also shorten the course of antibacterial treatment. Stolz et al (30) randomly divided 208 hospitalized AECOPD patients into the PCT-guided treatment group and standard antibiotic therapy group. For the PCT-guided treatment group, the serum PCT levels were used to decide the type of antibacterial drugs. For the standard antibiotic therapy group, the use and type of antibacterial drugs of the patients was based on the attending physician's experience. The results showed that the proportion of patients treated with antimicrobial drugs and the relative risk of exposure to antimicrobial agents in PCT-guided treatment groups (40\%; RR, 0.56) were both lower than those in standard antibiotic therapy group (72\%; RR, 0.76). This study showed significant differences in the two indexes between the two groups $(\mathrm{p}<0.0001)$, but no significant difference in prognosis was observed between the two groups. The above studies suggest that the increased PCT levels in patients with AECOPD may be associated with bacterial infections. These studies confirmed that the antimicrobial therapy of AECOPD can be guided by the PCT levels and can further safely reduce the use of antimicrobial agents in patients with lower respiratory tract bacterial infections. A prospective study conducted by Weis and Almdal (31) polled 166 hospitalized patients with acute exacerbations of COPD showing that the mean CRP level in 51 patients with pneumonia of bacterial origin was $97 \mathrm{mg} / \mathrm{l}$ and it was significantly higher than the normal range, suggesting CRP to be considered a biomarker of serious bacterial infection. Therefore, CRP levels can be used to guide the antibiotics treatment of AECOPD cases. Another retrospective study by Bircan et al (26), divided 51 patients with AECOPD into purulent sputum group $(n=25)$, sticky sputum group $(n=18)$ and sputum-free group $(n=8)$, based on the characters of sputum. The study concluded that the CRP level of sputum-free group was not significantly different from that of the sticky sputum group. However, the mean CRP level of purulent sputum group was significantly higher than that of the sticky sputum group $(p=0.015)$. The authors also concluded that the mean CRP levels of patients with leukocytosis was significantly higher than that of patients without leukocytosis, indicating that the increased serum CRP levels were correlated with increased purulent sputum and increased serum white blood cell count number. In our research study, PCT and hs-CRP levels of AECOPD patients with purulent sputum showed an increasing trend to those of the patients without purulent sputum, but no significant difference was observed between these two groups. The possible explanation can be the small sample size and short sampling time period, so it is necessary to increase the sample number for further study.

In conclusion, we believe that the serum PCT levels, and hs-CRP levels can be used as an auxiliary indicator in diagnosis of acute exacerbation of COPD. The measurement of serum PCT levels and hs-CRP levels of AECOPD patients may be helpful to guide antimicrobial treatment.

\section{References}

1. Sethi S. Pathogenesis and treatment of acute exacerbations of chronic obstructive pulmonary disease. Semin Respir Crit Care Med 26: 192-203, 2005.

2. Hirschmann JV. Do bacteria cause exacerbations of COPD? Chest 118: 193-203, 2000.

3. Murphy TF and Sethi S: Bacterial infection in chronic obstructive pulmonary disease. Am Rev Respir Dis 146: 1067-1083, 1992.

4. Monsó E, Ruiz J, Rosell A, Manterola J, Fiz J, Morera J and Ausina V: Bacterial infection in chronic obstructive pulmonary disease. A study of stable and exacerbated outpatients using the protected specimen brush. Am J Respir Crit Care Med 152: 1316-1320, 1995.

5. Burrows B and Earle RH: Course and prognosis of chronic obstructive lung disease. A prospective study of 200 patients. N Engl J Med 280: 397-404, 1969.

6. Sohy C, Pilette C, Niederman MS and Sibille Y: Acute exacerbation of chronic obstructive pulmonary disease and antibiotics: What studies are still needed? Eur Respir J 19: 966-975, 2002.

7. Nylén ES, Snider RH Jr, Thompson KA, Rohatgi P and Becker KL: Pneumonitis-associated hyperprocalcitoninemia. Am J Med Sci 312: 12-18, 1996.

8. Nijsten MW, Olinga P, The TH, de Vries EG, Koops HS, Groothuis GM, Limburg PC, ten Duis HJ, Moshage H, Hoekstra HJ, et al: Procalcitonin behaves as a fast responding acute phase protein in vivo and in vitro. Crit Care Med 28: 458-461, 2000

9. Somech R, Zakuth V, Assia A, Jurgenson U and Spirer Z: Procalcitonin correlates with C-reactive protein as an acute-phase reactant in pediatric patients. Isr Med Assoc J 2: 147-150, 2000.

10. Assicot M, Gendrel D, Carsin H, Raymond J, Guilbaud J and Bohuon C: High serum procalcitonin concentrations in patients with sepsis and infection. Lancet 341: 515-518, 1993.

11. Müller B, Becker KL, Schächinger H, Rickenbacher PR, Huber PR, Zimmerli W and Ritz R: Calcitonin precursors are reliable markers of sepsis in a medical intensive care unit. Crit Care Med 28: 977-983, 2000.

12. Vincent JL: Procalcitonin: THE marker of sepsis? Crit Care Med 28: 1226-1228, 2000.

13. Pearson TA, Mensah GA, Alexander RW, Anderson JL, Cannon RO III, Criqui M, Fadl YY, Fortmann SP, Hong Y, Myers GL, et al: Markers of inflammation and cardiovascular disease: application to clinical and public health practice: A statement for healthcare professionals from the Centers for Disease Control and Prevention and the American Heart Association. Circulation 107: 499-511, 2003.

14. Lin KH, Wang FL, Wu MS, Jiang BY, Kao WL, Chao HY, Wu JY and Lee CC: Serum procalcitonin and C-reactive protein levels as markers of bacterial infection in patients with liver cirrhosis: A systematic review and meta-analysis. Diagn Microbiol Infect Dis 80: 72-78, 2014.

15. Rangel-Frausto MS, Pittet D, Costigan M, Hwang T, Davis CS and Wenzel RP: The natural history of the systemic inflammatory response syndrome(SIRS). A prospective study. JAMA 273: 117-123, 1995.

16. Shimetani N, Ohba Y, Shimetani K, Mashiko T, Matsuyama N, Ohtani $\mathrm{H}$ and Morii M: Assay for determination of the serum procalcitonin level: Biochemical and clinical evaluation. Rinsho Byori 49: 56-60, 2001 (In Japanese).

17. Lieberman D, Lieberman D, Shmarkov O, Gelfer Y, BenYaakov M, Lazarovich Z and Boldur I: Serological evidence of Legionella species infection in acute exacerbation of COPD. Eur Respir J 19: 392-397, 2002.

18. Peng C, Tian C, Zhang Y, Yang X, Feng Y and Fan H: C-reactive protein levels predict bacterial exacerbation in patients with chronic obstructive pulmonary disease. Am J Med Sci 345: 190-194, 2013.

19. Polzin A, Pletz M, Erbes R, Raffenberg M, Mauch H, Wagner S, Arndt $\mathrm{G}$ and Lode $\mathrm{H}$ : Procalcitonin as a diagnostic tool in lower respiratory tract infections and tuberculosis. Eur Respir J 21: 939-943, 2003

20. Stolz D, Christ-Crain M, Gencay MM, Bingisser R, Huber PR, Müller B and Tamm M: Diagnostic value of signs, symptoms and laboratory values in lower respiratory tract infection. Swiss Med Wkly 136: 434-440, 2006. 
21. Pazarli AC, Koseoglu HI, Doruk S, Sahin S, Etikan I, Celikel S and Berktas B: Procalcitonin: Is it a predictor of noninvasive positive pressure ventilation necessity in acute chronic obstructive pulmonary disease exacerbation? J Res Med Sci 17: 1047-1051, 2012.

22. Tanrıverdi H, Örnek T, Erboy F, Altınsoy B, Uygur F, Atalay F and Tor MM: Comparison of diagnostic values of procalcitonin, C-reactive protein and blood neutrophil/lymphocyte ratio levels in predicting bacterial infection in hospitalized patients with acute exacerbations of COPD. Wien Klin Wochenschr 127: 756-763, 2015.

23. Yeh ET and Willerson JT: Coming of age of C-reactive protein: Using inflammation markers in cardiology. Circulation 107: 370-371, 2003

24. Dev D, Wallace E, Sankaran R, Cunniffe J, Govan JR, Wathen CG and Emmanuel FX: Value of C-reactive protein measurements in exacerbations of chronic obstructive pulmonary disease. Respir Med 92: 664-667, 1998.

25. Hurst JR, Donaldson GC, Perera WR, Wilkinson TM, Bilello JA, Hagan GW, Vessey RS and Wedzicha JA: Use of plasma biomarkers at exacerbation of chronic obstructive pulmonary disease. Am J Respir Crit Care Med 174: 867-874, 2006.

26. Bircan A, Gokirmak M, Kilic O, Ozturk O and Akkaya A: C-reactive protein levels in patients with chronic obstructive pulmonary disease: Role of infection. Med Princ Pract 17: 202-208, 2008
27. Stockley RA, O'Brien C, Pye A and Hill SL: Relationship of sputum color to nature and outpatient management of acute exacerbations of COPD. Chest 117: 1638-1645, 2000.

28. Gompertz S, O'Brien C, Bayley DL, Hill SL and Stockley RA: Changes in bronchial inflammation during acute exacerbations of chronic bronchitis. Eur Respir J 17: 112-1119, 2001.

29. Monsó E, Garcia-Aymerich J, Soler N, Farrero E, Felez MA, Antó JM and Torres A; EFRAM Investigators: Bacterial infection in exacerbated COPD with changes in sputum characteristics. Epidemiol Infect 131: 799-804, 2003.

30. Stolz D, Christ-Crain M, Bingisser R, Leuppi J, Miedinger D, Müller C, Huber P, Müller B and Tamm M: Antibiotic treatment of exacerbations of COPD: a randomized, controlled trial comparing procalcitonin-guidance with standard therapy. Chest 131: 9-19, 2007.

31. Weis $\mathrm{N}$ and Almdal T: C-reactive protein - can it be used as a marker of infection in patients with exacerbation of chronic obstructive pulmonary disease? Eur J Intern Med 17: 88-91, 2006. 